\title{
CHARACTERIZATION OF KERATINOPHILIC FUNGAL SPECIES AND OTHER NON-DERMATOPHYTES IN HAIR AND NAIL SAMPLES IN RIYADH, SAUDI ARABIA
}

\author{
Suaad S. Alwakeel \\ Department of Biology, College of Science, Princess Nourah bint Abdulrahman University, P.O. Box \\ 285876, Riyadh 11323, Saudi Arabia \\ Telephone: +966505204715 \\ Email: <ssalwakeel@pnu.edu.sa><dr.suaad@gmail.com>
}

\begin{abstract}
The presence of fungal species on skin and hair is a known finding in many mammalian species and humans are no exception. Superficial fungal infections are sometimes a chronic and recurring condition that affects approximately $10-20 \%$ of the world's population. However, most species that are isolated from humans tend to occur as co-existing flora. This study was conducted to determine the diversity of fungal species from the hair and nails of $\mathbf{2 4}$ workers in the central region of Saudi Arabia. Male workers from Riyadh, Saudi Arabia were recruited for this study and samples were obtained from their nails and hair for mycological analysis using Sabouraud's agar and sterile wet soil. A total of 26 species belonging to 19 fungal genera were isolated from the 24 hair samples. Chaetomium globosum was the most commonly isolated fungal species followed by Emericella nidulans, Cochliobolus neergaardii and Penicillium oxalicum. Three fungal species were isolated only from nail samples, namely, Alternaria alternata, Aureobasidium pullulans, and Penicillium chrysogenum. This study demonstrates the presence of numerous fungal species that are not previously described from hair and nails in Saudi Arabia. The ability of these fungi to grow on and degrade keratinaceous materials often facilitates their role to cause skin, hair and nail infections in workers and other persons subjected to fungal spores and hyphae.
\end{abstract}

Keywords: keratinophilic fungi, non-dermatophytes, mycobiota, hair, nails.

\section{INTRODUCTION}

Fungi with affinities to attack keratinized tissue are called "Keratinophilic fungi". These fungi are present in the environment of all over the world, specifically in keratin containing habitats where humans and animals are living. The biological function of keratinophilic fungi in the soil is the degradation of keratinized materials such as hides, furs, hair, feather, claws, nails, horns and skin debris of dead animals (Bisen and Tewari, 2015). The Keratinophilic fungi are basically saprophytes but occasionally becomes potentially pathogenic to man and animals. The pathogenic forms of fungi are known as "dermatophytes" and are known to cause superficial cutaneous infections (dermatophytoses) of keratinized tissues of humans and animals. Such fungi have better growth at temperatures of $25-28^{\circ} \mathrm{C}$ with warm 
and humid conditions. Infections by fungi are relatively common in tropical countries due to environmental, social and economic conditions. Superficial fungal infections are often chronic and recurring affecting approximately 10-20\% of the world's population is affected during their lifetime (Abanmi et al., 2008). Fungal infections of the skin, hair and nails are acquired via direct contact of other people, infected animals or fomites (Alsheikh, 2009). Dermatophytosis can either be caused by true dermatophytes (Microsporum, Trichophyton and Epidermophyton), yeasts (Candida), or moulds (e.g., Aspergillus, Alternaria, and Fusarium) (Sahin et al., 2004).

In various geographical locations, several studies have been conducted on characterization of fungi isolated from human hair and nails. In Turkey, T. rubrum, $T$. mentagrophytes, $T$. verrucosum and $T$. violaceum. Microsporum canis, M. gypseum, Epidermophyton floccosum, were commonly isolated from the hair and nails of students (Metintas and Kiraz, 2004). In northern Egypt, the most prevalent species included Aphanoascus, Aspergillus, Penicillium, Paecilomyces and Chrysosporium (Gherbawy et al., 2006). . In Northeast India, T. rubrum, $T$. mentagrophytes and M. gypseum were also the common isolates (Sarma, 2007). In Northern Greece, dermatophytes including Trichophyton rubrum (53.9\%), Trichophyton mentagrophytes (17.6\%), and Microsporum canis $(22.5 \%)$ were the most common isolates (Nasr et al., 2016). These studies demonstrate the wide variety of fungal species that exist as normal flora or possibly as colonizing non-pathological organisms.

Although, dermatophytic infections are a commonly encountered problem in Saudi
Arabia, very few studies are available about the specific species that cause these infections and even fewer exist describing the species (AlSogair et al., 1991 and Venugopal, 1992). In a study conducted among patients in Central Saudi Arabia, T. mentagrophytes, Candida spp. and Aspergillus spp. were found to be the most likely isolated species causing onychomycosis (Abanmi et al., 2008). Another study conducted in 2009 among patients clinically diagnosed with dermatophytic infections in an Eastern province of Saudi Arabia showed a variety of species including Epidermophyton floccosum, Trichophyton rubrum, Trichophyton schoenlenii, and the non-dermatophytes Candida albicans and Fusarium (Alsheikh, 2009) - Reports from Madina, Saudi Arabia (Hanafy, 2012) revealed that the most frequently isolated causal agents of cutaneous mycoses were Microsporum canis (15.4\%), Trichophyton metagrophytes (11.7\%), and Trichophyton violaceum (11\%). Screening for keratinolytic activity showed that $M$. canis and T. verrucosum recorded the highest value. In Riyadh City, Khaled et al. (2015) showed that Tinea capitis infection had the highest prevalence among the patients $(22.3 \%)$ while Tinea barbae had the lowest. The identified dermatophyte isolates were Trichophyton violaceum, Trichophyton verrucosum, Trichophyton rubrum, Trichophyton mentagrophytes, Trichophyton schoenleinii, Trichophyton concentricum, Microsporum canis, Microsporum audouinii and Epidermophyton floccosum. Non dermatophyte fungi included 5 isolates from Aspergillus, 4 isolates from Acremonium and 15 isolates from Candida. M. canis was the most common species (25\% of isolated dermatophytes). In Hail region of Saudi Arabia, Moursi (2016) 
conducted an epidemiological study of dermatophytic diseases and found that Trichophyton spp., are the predominant (82.11 $\%$ of cases) followed by Epidermophyton spp. (16.55 \%) but Microsporum spp., were the lowest (1.34\%). Among Tricophyton spp., T. mentegrophytes was more prevalent than $T$. rubrum $(68.55 \%$ and $31.45 \%$, respectively). More recently, Moursi et al. (2018) reported that dermatophytes are the major pathogens causing onychomycosis in Hail region. The prevalent yeast was represented by Candida albicans whereas the common nondermatophytic mold was $A$. niger.

The heterogeneity of the distribution pattern of dermatophytes in different parts of the world has been attributed to various factors, including climate, lifestyle, and the prevalence of immunodeficiency diseases in the community, as well as the reluctance of patients to seek treatment because of embarrassment or the minor nature of disease unless the condition became sufficiently serious to affect the quality of life (Al-Sogair et al., 1991 and Enugopal, 1992). Even fewer studies have attempted to understand the heterogeneity of the commensal fungi of the region due to their relative non-pathogenicity compared to the bacterial flora of the human body (Efuntoye and Fashanu, 2002). Hence, this study was conducted to determine the diversity and distribution of the commensal mycobiota from people living in Saudi Arabia in an attempt to characterize, classify and document these species and further understand their biology. The ability of some species to utilize keratin as an energy source i.e. keratinophilic fungi may aid in furthering our understanding of the interactions that fungi have with humans.

\section{MATERIALS AND METHODS}

1) Collection of hair and nail samples:

Twenty-four workers in Riyadh, Saudi Arabia were recruited as participants between January and March 2016. Their jobs included construction, menial work and operation of gas and petrol stations. Most of the recruited workers had spent at least a year in Saudi Arabia. We informed the participants of the aim and objectives of the study and obtained written informed consent. The study protocol was reviewed and approved by the Princess Nourah bint Abdulrahman University Research Ethics Committee IRB No. H-01- R059. Hair and nail samples were obtained from each worker using sterile instruments and collection bags.

2) Mycological analysis of human hair samples:

\section{i- Plating on Sabouraud's Dextrose Agar (SDA)}

Hair samples were individually placed on the surface of Sabouraud's Dextrose agar (SDA) which contained (g/l) glucose, 20, peptone, 10, agar, 20 and chloramphenicol, 0.5 according to the procedure described by Ellis et al. (2007). Chloramphenicol was incorporated into the medium to suppress bacterial growth. Cultures were incubated at $28^{\circ} \mathrm{C}$ for 1-3 weeks during which the growing fungi were examined and identified. Pure cultures of fungi were kept on slants containing the same medium for preservation and revision (Efuntoye and Fashanu, 2002).

\section{ii- Plating on sterile wet soil}

The hair baiting technique originally described by Vanbreuseghem (1952) was employed. A medium of About $1 \mathrm{~kg}$ of a clayey soil sample was autoclaved twice and 
distributed into sterile plastic Petri plates (30 grams/plate). Five $\mathrm{ml}$ of sterile distilled water was added to each. Fragments of hair samples were distributed on the soil surface, followed by incubation at $28^{\circ} \mathrm{C}$ and rewetting sterile water as required.. The plates were then examined for fungal growth and the fungi appearing on hair fragments were obtained and streaked on SDA medium for further identification. Slant cultures of fungal strains were also prepared for preservation.

\section{3) Mycological analysis of human nails samples:}

Nail samples were placed on the surface of SDA. Samples were incubated at $28^{\circ} \mathrm{C}$ for 1-3 weeks, during which the growing fungal cultures were examined and identified.

\section{4) Imaging of fungal species}

Wet slide preparations of fungal isolates were made using lactophenol cotton blue stain (LPCB). Fungi were examined under low and high magnification with an Axiostar binocular research microscope (Carl Zeiss Microscopy, GmbH, Germany). Images were taken with a Canon Power shot G6 digital camera (Canon, New York, USA).

\section{5) Identification of fungal cultures}

Fungi were identified based on their macroscopic and microscopic features using the following references: (Ellis, 1971; Moubasher, 1993, de Hoog et al., 2000, Domsch et al., 2007, and Ellis et al., 2007).

\section{RESULTS}

A total of 24 male workers participated in the study. The mean age was $34.1 \pm 5.8$ years and their ages ranged between 23 to 50 years. Twenty out of $24(83.3 \%)$ hair samples analysed produced fungal colonies when incubated and examined. The total number of isolates including those grown on SDA and in soil cultures was 49 . Of all the isolates, 26 species attributed to 19 fungal genera were identified. Isolates that grew dark sterile mycelia and budding yeasts were also included as shown in Tables $\left(\begin{array}{lll}1 & \&\end{array}\right)$. The number of isolates per sample ranged from 1 to 9 with the majority of samples yielding 1 or 2 species. Three samples yielded 3 species while the remaining positive samples produced 4, 6 or 9 fungal species (one sample for each).

Considering the frequency of occurrence of individual fungi on hair samples the present data showed that Chaetomium globosum was the most commonly isolated fungal species (7 samples representing $29 \%$ of hair samples matching $14.29 \%$ of total isolated fungi), followed by Emericella nidulans (4 samples representing $16.6 \%$ of samples matching 8.16\% of fungal isolates). Each of Cochliobolus neergaardii (anamorph= Bipolaris neergaardii) and Penicillium oxalicum appeared on 3 samples sharing with $6.12 \%$ of total isolated colonies. Unidentified yeasts were recovered from 5 hair samples cultured on SDA (Tables 1, 2 and Fig. 7).

When hair samples were cultured on sterile wet soil, 7 fungal strains appeared on the hair baits including Chaetomium globosum, Chrysosporium keratinophilum (Teleomorph= Aphanoascus fulvescens), Cladosporium cladosporioides, Cochliobolus neergaardii, $\mathrm{C}$. spicifer, Curvularia papendorfii, Stachybotrys chartarum in addition to an isolate of dark sterile myclia. This indicates the capacity of these isolates to degrade keratin and can be considered pathogenic causing skin and hair infections.

Regarding the fungi isolated from nail samples, only three species were identified 
including Alternaria alternata, Aureobasidium pullulans and Penicillium chrysogenum.

Microscopic examination and imaging of 19 different fungal strains from hair samples cultured on SDA or on sterile wet soil can be observed in 6 figures. Figure (1) illustrates the characteristic dark flexuous conidiophores and ellipsoidal conidia of Cochliobolus neergaardii, the dark geniculate conidiophore and cylindrical conidia of Cochliobolus spicifer (anamorph= Bipolaris spicifera $)$, and the chlamydospores and ellipsoidal conidia with transverse septa of Embellisia chlamydospora.

Figure (2) shows the pigmented conidiophore of Aspergillus nidulans (Teleomorph $=$ Emericella nidulans), the hyphae, microconidia and polyphialides of Fusarium chlamydosporum and the black, shining, smooth-walled conidia of Nigrospora oryzae $($ Teleomorph= Khuskia oryzae $)$.

Figure (3) illustrates the conidiogenous cells and conidia of Nodulisporium acervatum, the long metulae, cylindrical phialides and elliptical conidia of Penicillium oxalicum, the rebranched conidiophores of Penicillium chrysogenum and the dark pycnidium of Phoma herbarum.

Figure (4) shows the dark rosette-shaped phialides, conidiophores and dark conidia of Stachybotrys chartarum as well as the dark coloured geniculate conidiogenous cells and the solitary muriform conidia of Ulocladium botrytis.

Figure (5) shows the following: a. Alternaria alternata producing branched chains of dark conidia with transverse and longitudinal septa; b. Aspergillus sydowii with hyaline vesiculate conidiophores, biseriate conidial heads, metulae and phialides producing chains of echinulate conidia; $c$. the pigmented conidiophores of Aspergillus ustus with biseriate conidial heads and rough-walled conidia; and d. growth of Chaetomium globosum on a human hair fragment showing dark perithecial ascoma and ascospores.

Figure (6) illustrates the following: a. Chaetomium globosum with dark subglobose perithecial ascomata with lateral and terminal hairs. Dark olive-brown lemon shaped ascospores; b. Fungal growth on human hair fragments plated on wet sterile soil; c. growth of Chrysosporium keratinophilum on human hair showing hyaline hyphae that produce intercalary and lateral ovoid spores each with truncate base; and d. growth of Curvularia papendorfii on a human hair fragments.

\section{DISCUSSION}

Human skin, which includes structures such as hair and nails, supports the growth of a varied fungal flora, not only dermatophytes and yeasts but also other species of moulds. The biggest group of organisms that can utilize keratin as the sole source of carbon and nitrogen are the keratinophilic fungi. In the present study the diversity of this interesting group of fungi was studied in hair and nail samples from 24 male workers in Riyadh. These fungi cab easily transmitted from the environment to human hair and nails as well as to other body sites. Pandey et al. (1989) conducted a survey of pathogenic fungi in $\mathbf{4 5}$ soil samples collected from forest, riverside and residential garbage soil in Jabalpur, India. They isolated 66 fungal species classified in $\mathbf{3 5}$ genera which included representative species of Chrysosporium (78\%), Fusarium (69\%), Aspergillus (47\%), Penicillium (11\%), Cladosporium (7\%) and Chaetomium (4\%).

Among the 26 fungal species isolated and identified during the present study 
Chaetomium globosum was the most common fungus (29\% of samples). This species was previously described as a cause of onychomycosis in Spain (Aspiroz et al., 2007), Czeck Republic (Hubka et al., 2011), Korea (Kim et al., 2013) and China (Shi et al., 2016). C. globosum produces mycotoxins, particularly chaetoglobosins $A$ and $C$ when cultured on building materials (Fogle et al., 2007). Together with Stachybotrys charatarum, $C$. globosum was frequently found growing on wooden materials and was involved in fungal infections amongst construction workers causing a disease named as "sick building syndrome" (Straus, 2011).

Emericella nidulans which occurred in $16.6 \%$ of our samples constituting $8.16 \%$ of fungal isolates has been recently found to cause endophthalmitis after cataract surgery which showed no improvement with vigorous topical and intravitreal therapy (Mutlu et al., 2016). Cochliobolus neergaardii is a fungus that is associated with rice seeds and is usually found in the Asian temperate zones such as Saudi Arabia and the Arabian peninsula, and has been known to cause devastating disease epidemics on food crops, such as rice, wheat and maize (Otaka et al., 2016). Penicillium oxalicum was found in $\mathbf{1 2 . 5 \%}$ of our samples. Exposure to spores of Penicillium oxalicum may provoke adverse health effects such as allergic rhinitis, bronchial asthma or extrinsic allergic alveolitis (Lugauskas et al., 2004).

Onychomycosis is documented to result from Aspergillus sydowii and Ulocladium botrytis (Romano et al., 2004; NouripourSisakht et al., 2015). Cases of fungal endophthalmitis from Aspergillus terreus and Emericella nidulans were reported by Mutlu et al. (2016) and Puah et al. (2016). Pulmonary infections from Aspergillus ustus and Stachybotrys charatarum (Hodgson et al., 1998; Cabada et al., 2010), infection of the lymphatic system from Aureobasidium pullulans (de Morais et al., 2011), haemorrhagic pneumonia from Cladosporum cladosporioides (Grava et al., 2016), perinephric abscesses from Fusarium chlamydosporum (Sidhu et al., 2013) and intestinal disseminated disease from Penicillium chrysogenum (Barcus et al., 2005) were frequently documented. The large percentage of the isolated species that could potentially cause a human infection should be seriously considered. Mycological infections usually receive less attention than bacterial and viral infections, but the potential for these fungi to infect humans with their added ubiquity should be taken seriously (Tsoumani et al., 2011).

Additional studies on fungal isolation from hair and nails in different parts of the world have been conducted in Turkey (Metintas et al., 2004), India (Sarma, 2007), Czech Republic (Lysková, 2007) and in Northern Greece (Nasr et al., 2016), The non-dermatophytes characterized in our study have also shown more diversity and were more prevalent in our samples. This diversity in fungal isolates supports the hypothesis that heterogeneity of the distribution may be due to differences in climate and lifestyle (Al-Sogair et al., 1991; Enugopal, 1992; Alsheikh., 2009). More recently, Kutwal and Sambali (2016) were able to isolate Aspergillus sydowi, A. ustus, A. stellatus (= Emericella vriecolor $)$ and Cladosporium cladosporioides as active keratinolytic fungi growing on human hair. Reports from Libya (Altayyar et al., 2016) showed that Aspergillus species were the highest isolated $(\mathbf{5 8 . 9 \%})$ followed by 
Acremonium spp. (14.8\%), Chrysosporium spp. (8.9\%), Trichoderma spp. (5.8\%), Microsporum spp. (2.9\%) and Mucor spp. (2.9\%).

As mentioned by Piraccini and Alessandrini (2015) onychomycosis is the most common nail infective disorder, and it is responsible for about $50 \%$ of all consultations for nail disorders. Onychomycosis has been reported as a gender- and age-related disease, being more prevalent in males and increasing with age in both genders. In the elderly, onychomycosis may have an incidence $>40 \%$. Predisposing factors are diabetes mellitus, peripheral arterial disease, immunosuppression due to HIV or immunosuppressive agents. In most cases, this infection is caused by anthropophilic dermatophytes, in particular by Trichophyton rubrum, followed by Trichophyton mentagrophytes var. interdigitale. Nondermatophyte molds, like Scopulariopsis brevicaulis and Aspergillus spp., can be involved in onychomycosis as primary pathogens or as contaminant agents and secondary pathogens (Gherbawy et al., 2006). Other molds that have been isolated from affected nails include Fusarium spp., Acremonium spp. and Alternaria spp. The estimated worldwide prevalence of nondermatophyte molds onychomycosis is $10 \%-$ 15\%. Yeasts, like Candida albicans and Candida parapsilosis, represent the third cause of nail fungal infection, and they occur only when predisposing factors are present, mainly immunosuppression and diabetes.

\section{CONCLUSIONS}

A diverse population of potentially pathogenic and non-pathogenic nondermatophyte fungal species was isolated from the hair and nails of Saudi Arabian workers.
These fungi were characterized and identified microscopically. The presence of these fungal species, their distribution amongst human hosts, their contributions to the normal flora of the skin and its appendages and their possible pathogenicity warrant further large scale study. Identifying these species and describing them morphologically with high definition images makes this study the first of its kind in the region.

\section{ACKNOWLEDGMENTS:}

I would like to thank the Director of Assiut University Mycological Centre (AUMC) and research team for their great efforts in checking identification of fungal species and imaging of selected strains.

\section{REFERENCES}

Abanmi, A., Bakheshwain, S., El Khizzi, N., Zouman, A.R., Hantirah, S., Al Harthi, F., Al Jamal, M., Rizvi, S.S., Ahmad, M., Tariq, M. (2008): Characteristics of superficial fungal infections in the Riyadh region of Saudi Arabia. International Journal of Dermatology, 47: 229-235.

Al-Sogair, S. M., Moawad, M. K. and alHumaidan, Y. M. (1991): Fungal infection as a cause of skin disease in the eastern province of Saudi Arabia: prevailing fungi and pattern of infection. Mycoses, 34(7-8): 333-337.

Alsheikh H. (2009): Epidemiology of Dermatophytes in the Eastern province of Saudi Arabia. Research Journal of Microbiology, 4(6): 229-234.

Altayyar I. A. , Osman N. A, e Elbreki M. F. , Ibrahim H. A., Aboalasad A., Barkah. A and Almahdi N. (2016): Isolation and Identification of Soil Keratinophilic Fungi from Different Area in South of Libya. International Journal of Applied Medical and Biological Research, 1 (1): 27-32. 
Aspiroz C., Gene J. , Rezusta A. ,Charlez L., Summerbell R.C. (2007): First Spanish case of onychomycosis caused by Chaetomium globosum. Medical Mycology, 45: 279 - 282.

Bisen P. and Tiwari S. (2015): A Review on Keratinophilic Fungi of Madhya Pradesh. IOSR Journal of Pharmacy and Biological Sciences (IOSR-JPBS) 10 (6): 18-22.

Barcus, A. L., Burdette, S. D. and Herchline, T. E. (2005): Intestinal invasion and disseminated disease associated with Penicillium chrysogenum. Annals of Clinical Microbiology and Antimicrobials, 4(21): 1-4.

Cabada M. M., Nishi S. P., , Lea A. S., Schnadig V., Lombard G. A., Lick S. D., Valentine V. G. (2010): Concomitant pulmonary infection with Nocardia transvalensis and Aspergillus ustus in lung transplantation. Journal of Heart and Lung Transplantation, 29(8): 900-903.

de Hoog G.S., Guarro J., Gene J., Figueras M.J. (2000): Atlas of clinical fungi. 2nd ed. Centraalbureau voor Schimmelcultures, Amsterdam, 1126 pp.

Domsch K.H., Gams W. and AndersonT.H. (2007): Compendium of soil fungi 2 nd ed. IHW-Verlg Eching, Germany, 672 pp.

Efuntoye M. O. and Fashanu, S. O. (2002): Occurrence of keratinophilic fungi and dermatophytes on domestic birds in Nigeria. Mycopathologia, 153(2): 87-89.

Ellis D., Davis S., Alexiou H., Handke R. B. R. (2007): Description of medical fungi, Mycology Unit, Women`s and Children`s Hospital, University of Adelaide, Australia.178 pp.

Ellis, M.B. (1971): Dematiaceous Hyphomycetes. Commonwealth Mycological Institute: Kew, Surrey, UK, 608 pp.
Fogle M.R., Douglas ～D.R., Jumper C.A., Straus D.C. (2007): Growth and mycotoxin production by Chaetomium globosum. Mycopathologia. 164(1):49-56.

Gherbawy Y.A., Maghraby T.A., ElSharouny H.M. (2006): Diversity of keratinophilic fungi on human hairs and nails at four Governorates in Upper Egypt. Mycobiology, 34(4): 180-184.

Grava S., Lopes, F. A. D., Cavallazzi, R. S., Grassi, M. F. N. N. and Svidzinski T. I. E. (2016): A rare case of hemorrhagic pneumonia due to Cladosporium cladosporioides, 42(5): 392-394.

Hanafy A. M. M., El-Adly A. A., Alsarani A. A. Q., Ashfaq M. and Karam El-Din A. A. (2012: Epidemiology of cutaneous mycosis in the Medina region of Saudi Arabia correlated with studying the effect of light-induced gold nanoparticles on the growth of dermatophytes in vitro. African Journal of Microbiology Research, 6(37): 6668-6677.

\begin{tabular}{|c|c|c|}
\hline Hodgson & M.J., Morey & P., Leung \\
\hline W.Y., Mor & L., Miller & D., Jarvis \\
\hline . B & H., Halsey & Storey \\
\hline
\end{tabular}
(1998): Building-associated pulmonary disease from exposure to Stachybotrys chartarum and Aspergillus versicolor. Journal of Occupational and Environmental Medicine, 40(3): 241-249.

Hubka V., Mencl K., Skorepova M., Lyskova P. and Zalabska E. (2011): Phaeohyphomycosis and onychomycosis due to Chaetomium spp., including the first report of Chaetomium brasiliense infection Medical Mycology, 49: 724-733.

Khaled J.M., Golah H.A., Khalel A.S., Alharbi N.S., Mothana R.A. (2015): Dermatophyte and non dermatophyte fungi in Riyadh City, Saudi Arabia. Saudi Journal of Biological Science, 22(5): 604-609. 
Kim D. M., Lee M. H., Suh M. K., Ha G. Y., Kim H., Choi J. S. (2013): Onychomycosis caused by Chaetomium globosum. Annals of Dermatology 25: 232-236.

Kotwal S. and Sumbali G. (2016): Preferential utilization and colonization of keratin baits by different myco keratinophiles. Kotwal and Sumbali SpringerPlus, 5:1-6.

Lugauskas, A., Krikštaponis, A. and Šveistyte, L. (2004) 'Airborne fungi in industrial environments - Potential agents of respiratory diseases. Annals of Agriculture and Environmental Medicine, 11(1): 1925.

Lysková, P. (2007): Saprotrophic microscopic fungi and dermatophytes accompanying infections of the skin and nails of patients in the Moravian-Silesian Region (Czech Republic), Czech Mycology, 59(1): 125137.

Metintas S., Kiraz N. (2004): Frequency and risk factors of dermatophytosis in students living in rural areas in Eskisehir, Turkey. Mycopathologia, 157(4): 379-382.

de Morais O.O. Porto C. , Coutinho A. S. S., Reis C. M. S., Teixeira M. M. and Gomes C. M. (2011): Infection of the lymphatic system by Aureobasidium pullulans in a patient with erythema nodosum leprosum, Brazilian Journal of Infectious Diseases, 15(3), pp. 288292.

Moubasher, A. H. (1993) Soil fungi in Qatar and other Arab countries. The Center of Scientific and Applied Research, University of Qatar, Doha, Qatar.566 pp.

Moursi S. A. (2016): Epidemiological studies on dermatophytosis in human in Hail region of Saudi Arabia. IOSR Journal of Dental and Medical Sciences (IOSR-JDMS) 15(2): 80-84.
Moursi S. A., Al Baqawi R. A., Al shammari M. N. , Al Enzi N. S. (2018): Prevalence of onychomycosis in Hail region, Saudi Arabia. National Journal of Laboratory Medicine. 7(2): 1-5.

$\begin{array}{crr}\text { Mutlu } & \text { F.M., Yildiran } & \text { S.T., Saracli } \\ \text { M.A., Gümral } & \text { R., Durukan } & \text { H., Sobaci }\end{array}$ G., Mutlu A.G.. (2016): Premier cas rapporté d'endophtalmie fongique causée par Emericella nidulans après chirurgie de la cataracte. Journal de Mycologie Medicale, 26(3): 271-276.

Nasr A., Vyzantiadis T.A., Patsatsi A., Louka A., Ioakimidou A., Zachrou E., Chavale A., Kalabalikis D., Malissiovas N., Sotiriadis D. (2016): Epidemiology of superficial mycoses in Northern Greece: A 4year study. Journal of the European Academy of Dermatology and Venereology, 30(5), pp. 837-839.

Nouripour-Sisakht S., Mirhendi H., Shidfar M.R., Ahmadi B., Rezaei-Matehkolaei A., Geramishoar M., Zarei F. and Jalalizand N. (2015): Aspergillus species as emerging causative agents of onychomycosis. Journal de Mycologie Medicale, 25(2): 101-107.

Otaka, J., Seo, S. and Nishimura, M. (2016): Lutein, a natural carotenoid, induces $\alpha$ 1,3- glucan accumulation on the cell wall surface of fungal plant pathogens. Molecules, 21(8).

Pandey A, Agrawal GP and Singh SM (1989): Pathogenic fungi in soils of Jabalpur, India; Mycoses, 33(3): 116-125.

Piraccini B M. and Alessandrini A. (2015): Onychomycosis: A Review Journal of Fungi 1, 30-43.

Puah S.H., Ng J., Ang B., Xu H., Agrawal R. H. S. (2016): Recurrent Aspergillus terreus Endophthalmitis from Focal Bronchiectasis, 
Ocular Immunology and Inflammation, 11: 14.

Romano C, Maritati E, Paccagnini E, M. L. (2004): Onychomycosis due to Ulocladium botrytis. Mycoses, 47(7): 346-348.

Sahin, I., Oksuz S., Kaya D., Sencan I. and Cetinkaya R. (2004): Dermatophytes in the rural area of Duzce, Turkey. Mycoses, 47: 470474.

Sarma S, B. A. (2007) 'A clinicoepidemiological study of dermatophytoses in Northeast India.', Indian journal of dermatology, venereology and leprology., 73(6): 427-428.

Shia D., Lu G., Mei H., de Hoog G. S., Zheng H., Liang G., Shen Y., Lia T., Liu W. (2016): Onychomycosis due to Chaetomium globosum with yellowish black discoloration and periungual inflammation. Medical Mycology Case Reports, 13: 12-16.

Sidhu, S., Chander, J. and Singh, K. (2013): Perinephric abscess caused by
Fusarium chlamydosporum in an immunocompetent child: Case report and identification of the morphologically a typical fungal strain'. Indian Journal of Pathology and Microbiology, 56(3): 312.

Straus D. C. (2011): The possible role of fungal contamination in sick building syndrome. Front Bioscience 1(3): 562-580.

Tsoumani M., Jelastopulu E., Bartzavali C, Vamvakopoulou S., Dimitracopoulos G., Anastassiou E. D and Christofidou M. (2011): Changes of Dermatophytoses in Southwestern Greece: An 18-Year Survey. Mycopathologia, 172(1): 63-67.

Vanbreuseghem R. (1952): Technique biologique pour I' isolement des dermatophytes dusol. Annales de la Société Belge de Médecine Tropicale 32:173-78.

Venugopal P. V. and Venugobal T. V. (1992): Superficial mycoses in Saudi Arabia, Australasian Journal of Dermatology, 33(1): 45-8. 
Table 1. Fungal species isolated from human hair samples on SDA (A) and sterile wet soil (B) and their frequency out of 24 samples.

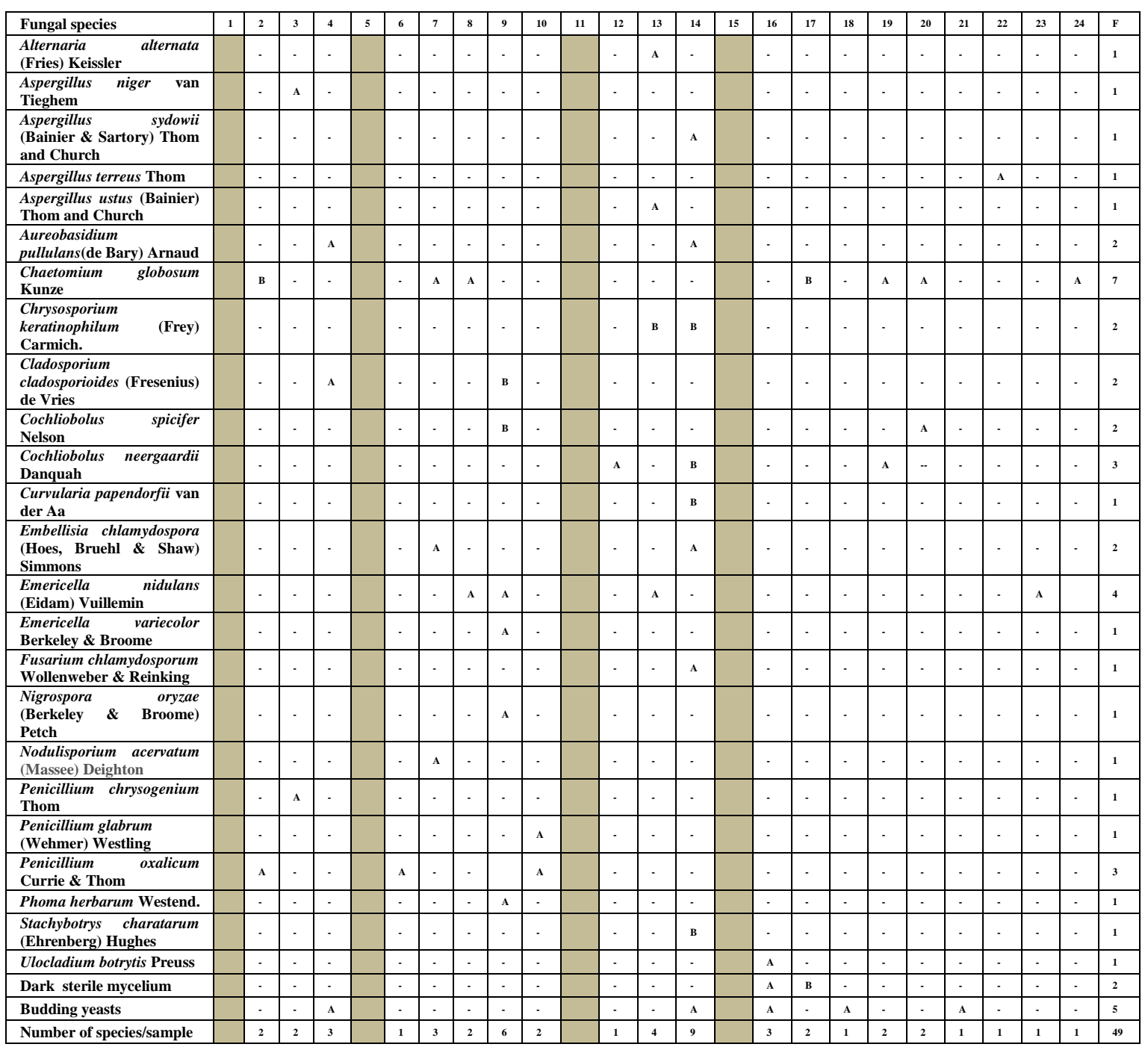

Hair samples showing negative results are highlighted (four samples) 
Table 2: Incidence (out of 24 samples from male workers) of fungal species recovered from hair and nail samples on SDA and sterile wet soil (SWS).

\begin{tabular}{|c|c|c|c|c|}
\hline \multirow{2}{*}{ Fungal species } & \multicolumn{3}{|c|}{ Hair } & \multirow{2}{*}{$\begin{array}{l}\text { Nails } \\
\text { SDA }\end{array}$} \\
\hline & SDA & SWS & Total & \\
\hline Alternaria alternate (Fries) Keissler & 1 & - & 1 & 1 \\
\hline Aspergillus niger van Tieghem & 1 & - & 1 & - \\
\hline Aspergillus sydowii (Bainier\&Sartory) Thom and Church & 1 & - & 1 & - \\
\hline Aspergillus terreus Thom & 1 & - & 1 & - \\
\hline Aspergillus ustus(Bainier) Thom and Church & 1 & - & 1 & - \\
\hline Aureobasidium pullulans (de Bary) Arnaud & 2 & - & 2 & 1 \\
\hline Chaetomium globosum Kunze & 5 & 2 & 7 & - \\
\hline Chrysosporium keratinophilum (Frey) Carmich. & - & 2 & 2 & - \\
\hline Cladosporium cladosporioides (Fresenius) de Vries & 1 & 1 & 2 & - \\
\hline Cochliobolus spicifer Nelson & 1 & 1 & 2 & - \\
\hline Cochliobolus neergaardii Danquah & 2 & 1 & 3 & - \\
\hline Curvularia papendorfii van der Aa & - & 1 & 1 & - \\
\hline Embellisia chlamydospora(Hoes, Bruehl\& Shaw) Simmons & 2 & - & 2 & - \\
\hline Emericella nidulans (Eidam) Vuillemin & 4 & - & 4 & - \\
\hline Emericella variecolor Berkeley \& Broome & 1 & - & 1 & - \\
\hline Fusarium chlamydosporum Wollenweber \& Reinking & 1 & - & 1 & - \\
\hline Nigrospora oryzae (Berkeley \& Broome) Petch & 1 & - & 1 & - \\
\hline Nodulisporium acervatum (Massee) Deighton & 1 & - & 1 & - \\
\hline Penicillium chrysogenum Thom & 1 & - & 1 & 1 \\
\hline Penicillium glabrum(Wehmer) Westling & 1 & - & 1 & - \\
\hline Penicillium oxalicum Currie \& Thom & 3 & - & 3 & - \\
\hline Phoma herbarum Westend. & 1 & - & 1 & - \\
\hline Stachybotrys charatarum (Ehrenberg) Hughes & - & 1 & 1 & - \\
\hline Ulocladium botrytis Preuss & 1 & - & 1 & - \\
\hline Dark sterile mycelium & 1 & 1 & 2 & - \\
\hline Budding yeasts & 5 & - & 5 & - \\
\hline Total number of fungal strains & 39 & 10 & 49 & 3 \\
\hline
\end{tabular}




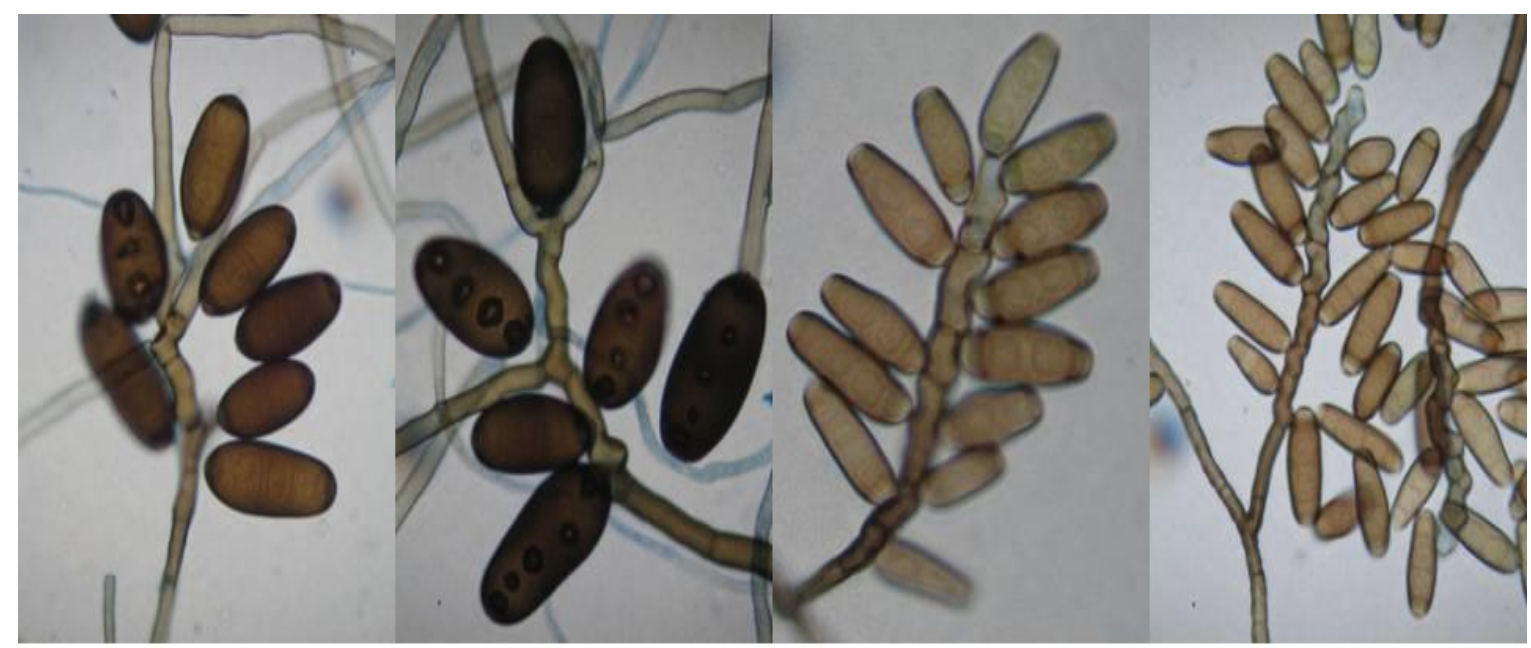

Cochliobolus neergaardii: Dark flexuous conidiophores and broadly ellipsoidal, 3 septate conidia

Cochliobolus spicifer: Dark geniculate conidiophores and cylindrical 3 septate conidia.

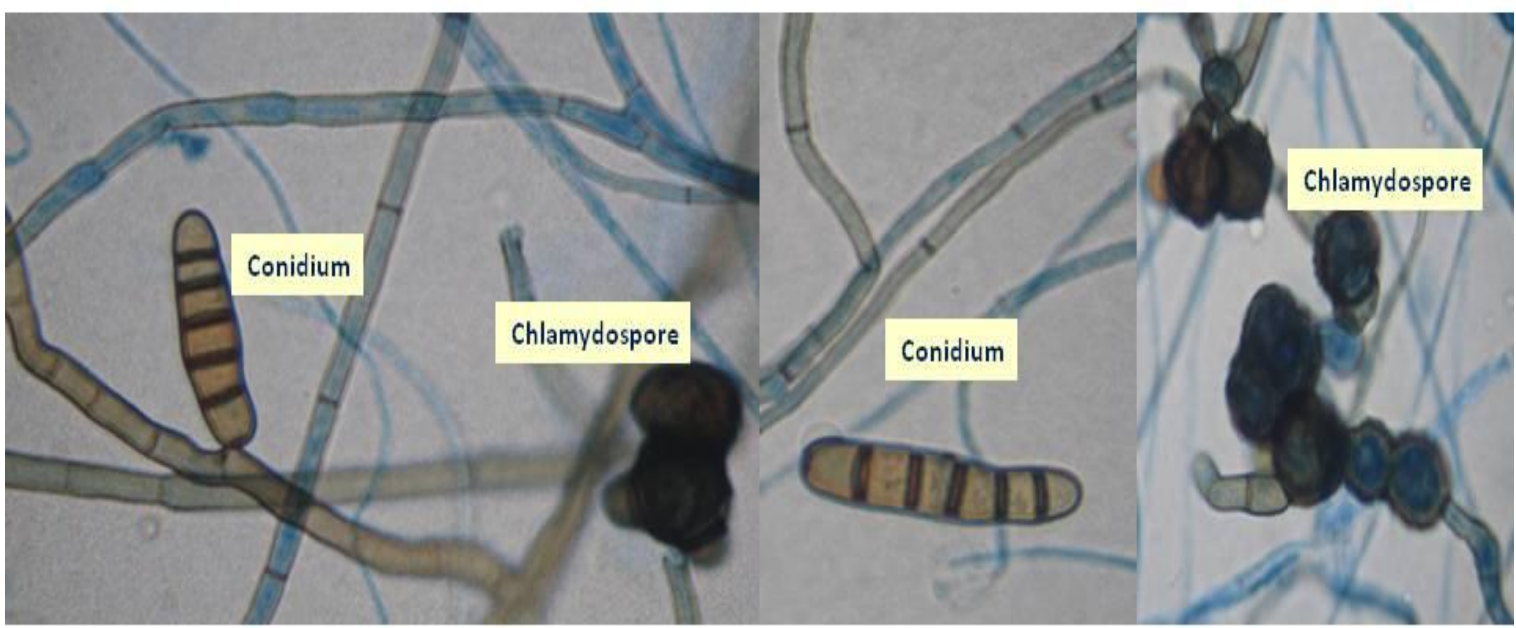

Embellisia chlamydospora: Ellipsoidal dark conidia with 5 thick transverse septa

Embellisia chlamydospora: Dark septate conidium (left) and chlamydospores of variable size and shape (right)

Figure 1. Microscopic images of some fungal species belonging to Cochliobolus, and Embellisia (X1000) isolated from the hair of workers 


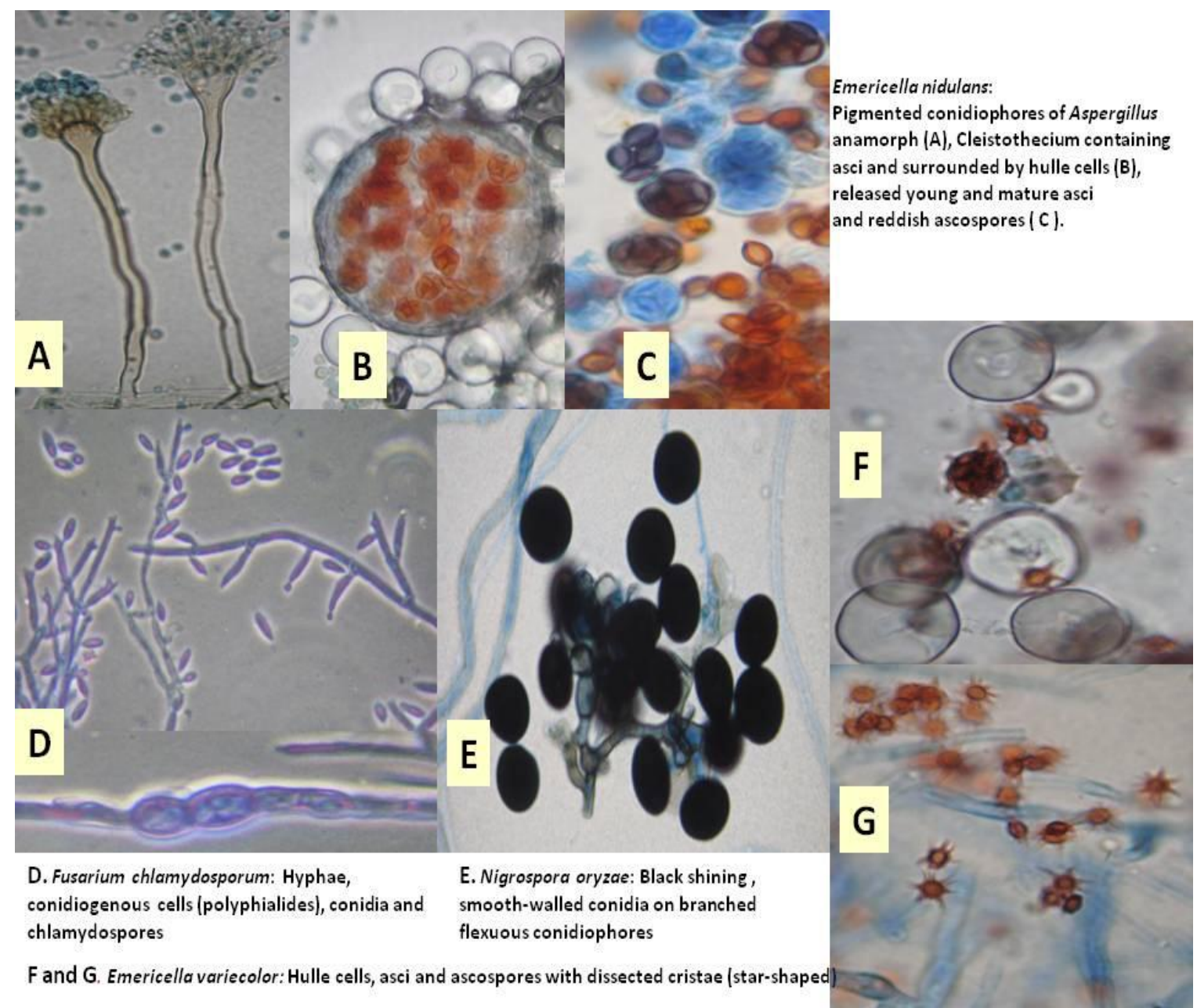

Figure 2. Microscopic images of some fungal species belonging to Emericella, Fusarium and Nigrospora (X1000) isolated from the hair of workers 


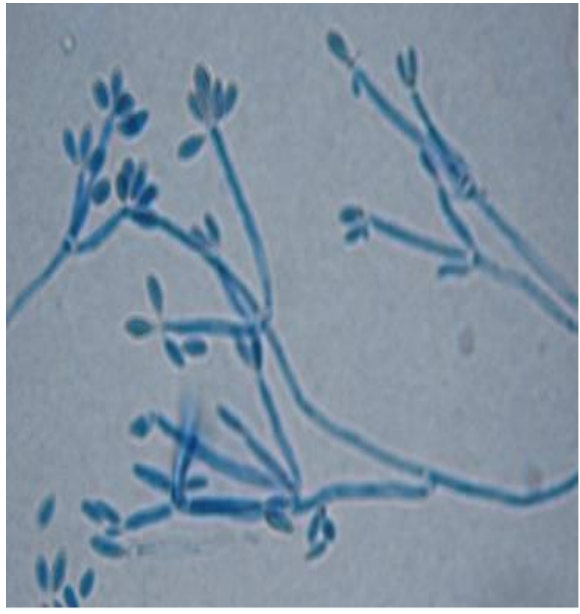

Nodulisporium acervatum: Conidiophores, conidiogenous cells and conidia

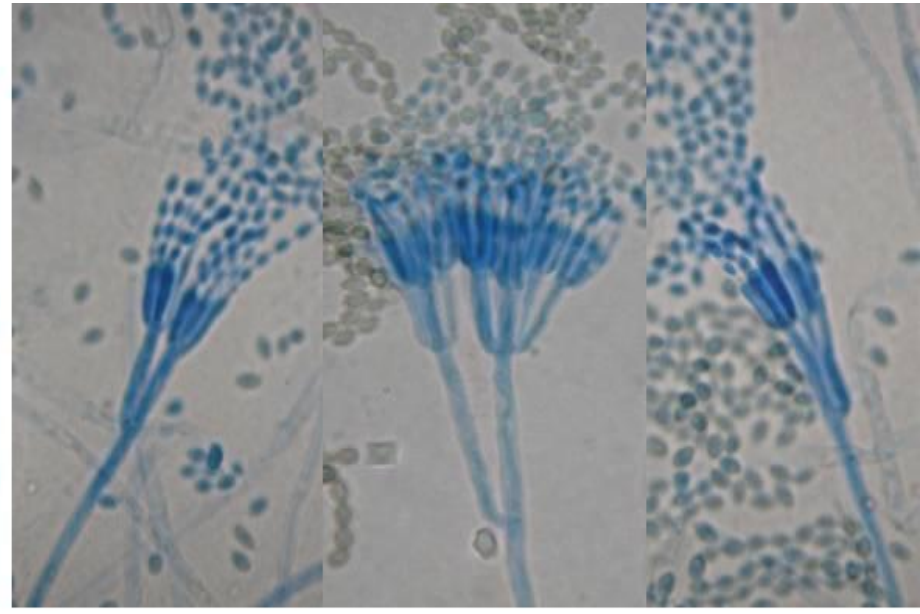

Penicillium oxalicum: Conidiophores with long metulae and cylindrical phialides producing chains of strongly elliptical smooth-walled conidia.

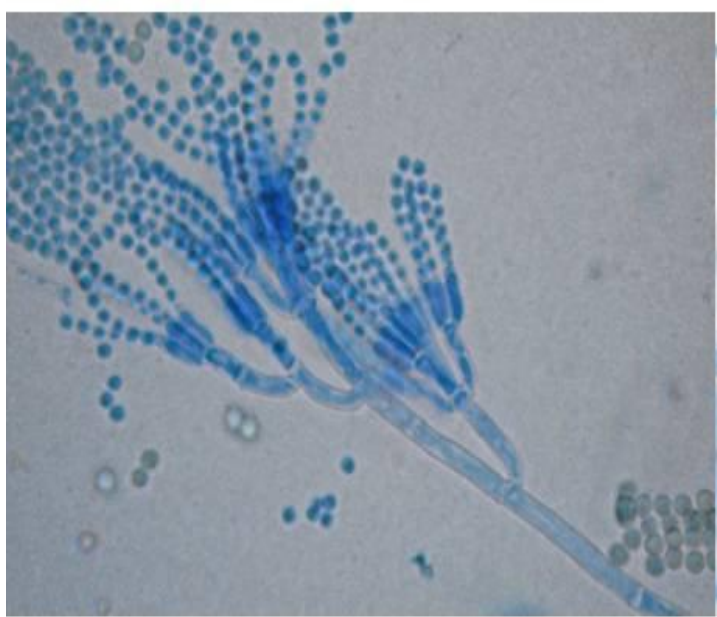

Penicillium chrysogenum: Rebranched conidiophore, metulae, phialides and conidial chains

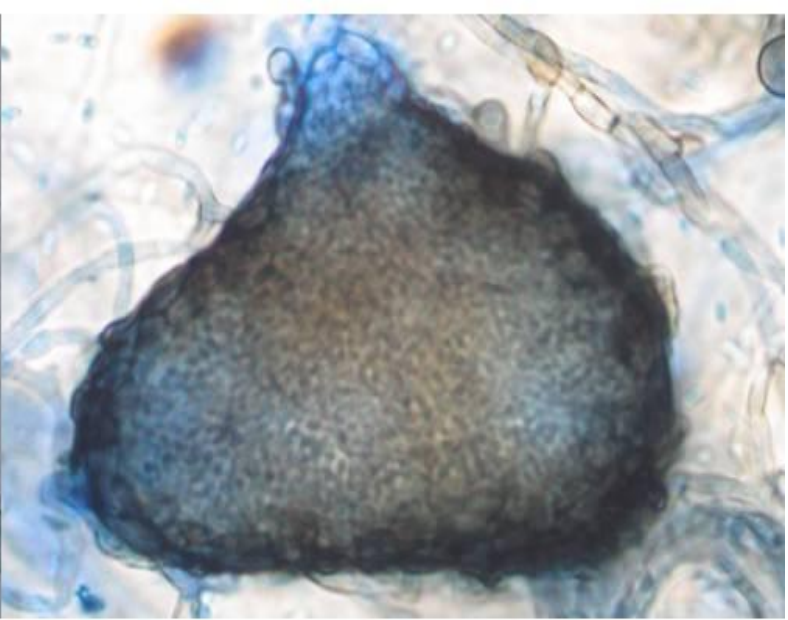

Phoma herbarum: A dark coloured pycnidium and hyaline ellipsoidal conidia

Figure 3. Microscopic images of some fungal species belonging to Nodulisporium, penicillium and Phoma (X1000) isolated from the hair of workers 


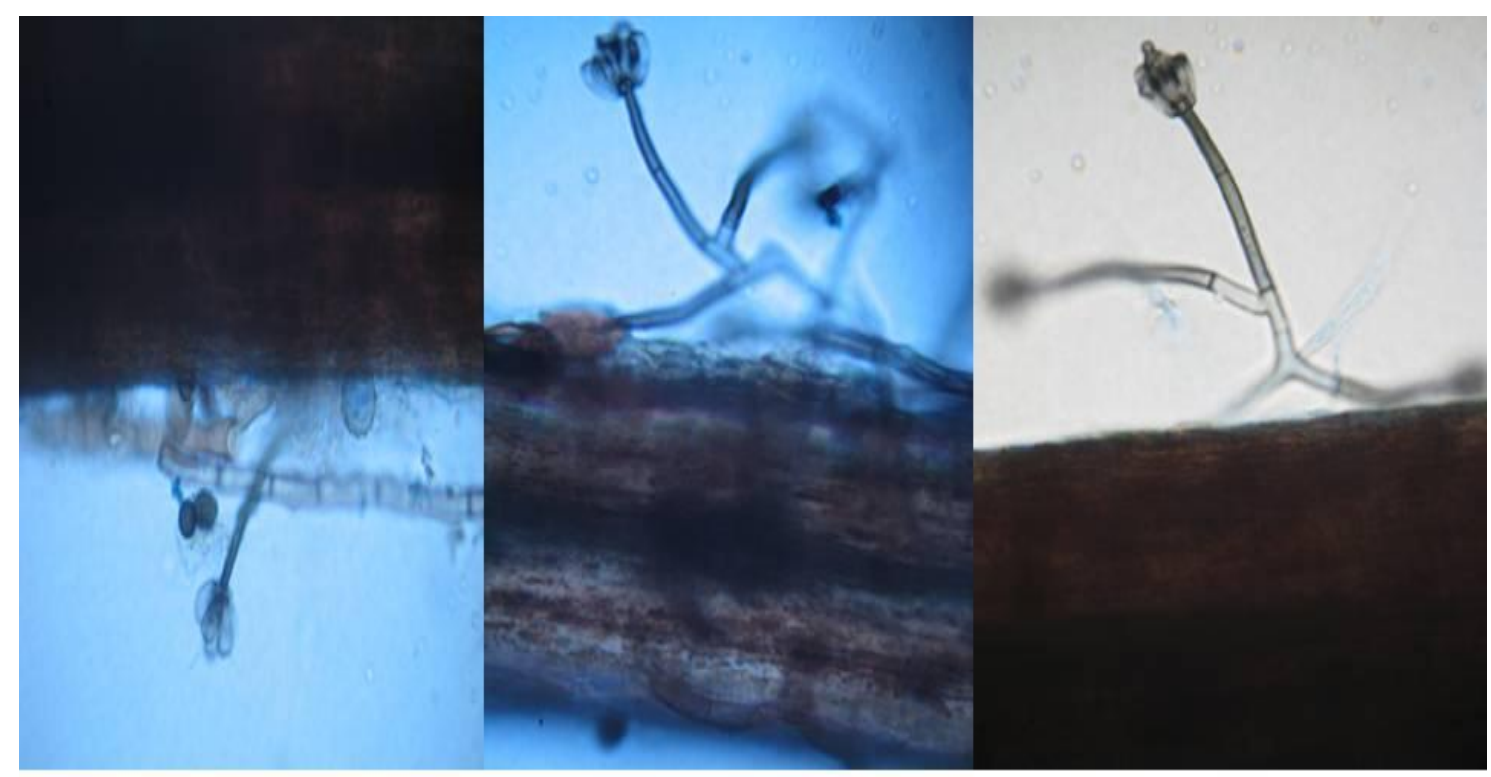

Growth of Stachybotrys chartarum on human hair fragment showing dark phialides and conidiophores.

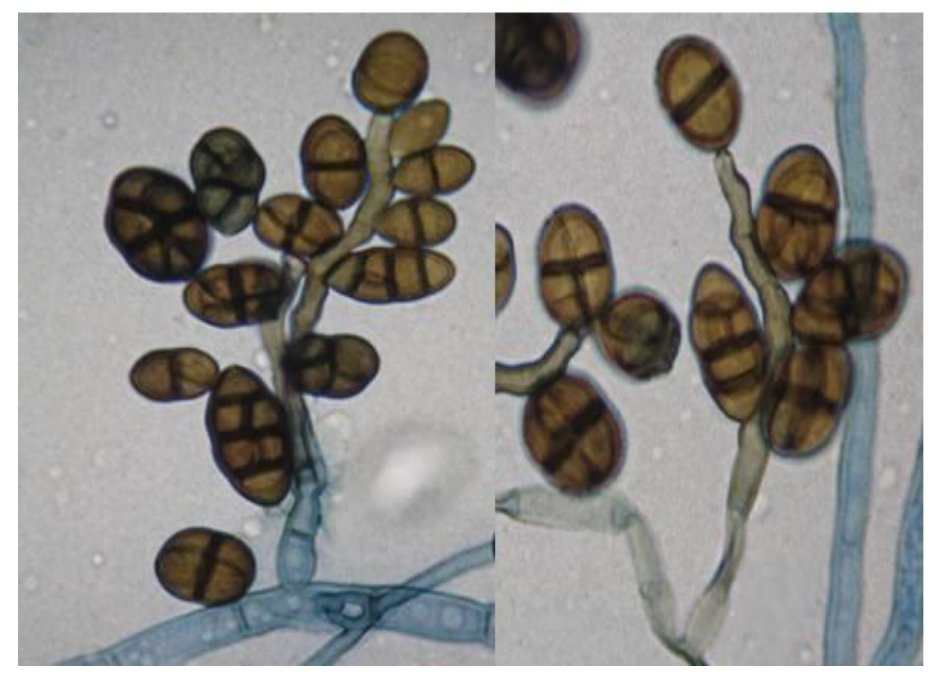

Ulocladium botrytis:

Dark conidiophores (geniculate)

and solitary muriform conidia

Figure 4. Microscopic images of some fungal species belonging to Stachybotrys and Ulocladium (X1000) isolated from the hair of workers 


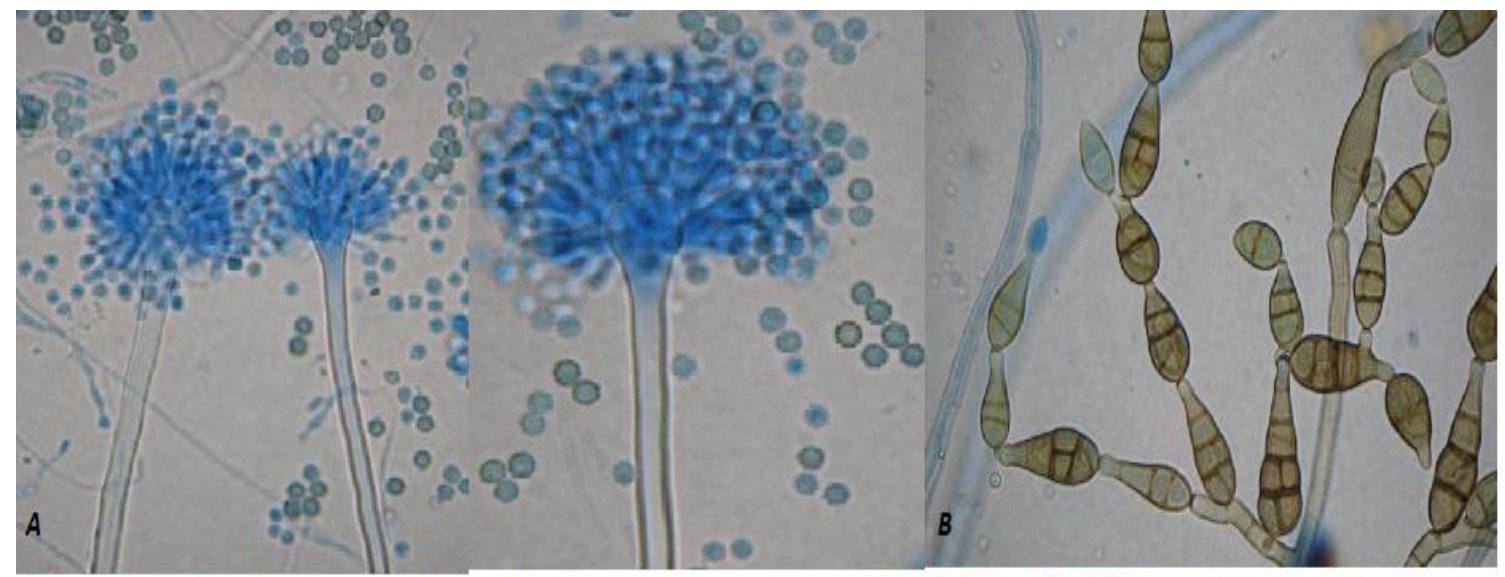

Aspergillus sydowii: Hyaline vesiculate conidiophores, biseriate conidial heads Alternaria alternata: Branched chains of dark with metulae and phialides producing chains of echinulate conidia. conidia with transverse and longitudinal septa

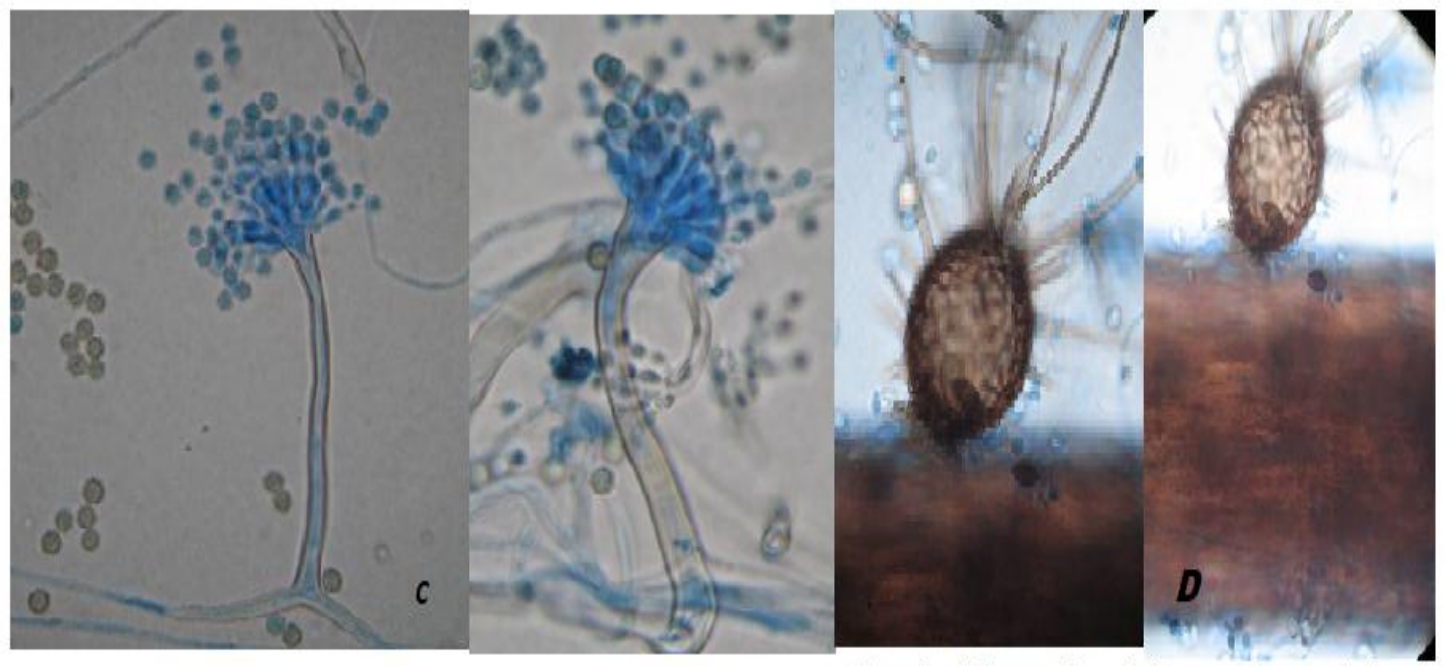

Growth of Chaetomium globosum on human hair Aspergillus ustus: Pigmented conidiophores with conidial heads and rough fragment conidia

Figure 5. Microscopic images of some fungal species belonging to Aspergillus, Alternaria (X1000) and Chaetomium (X1000 left and X 400 right) isolated from the hair of workers 


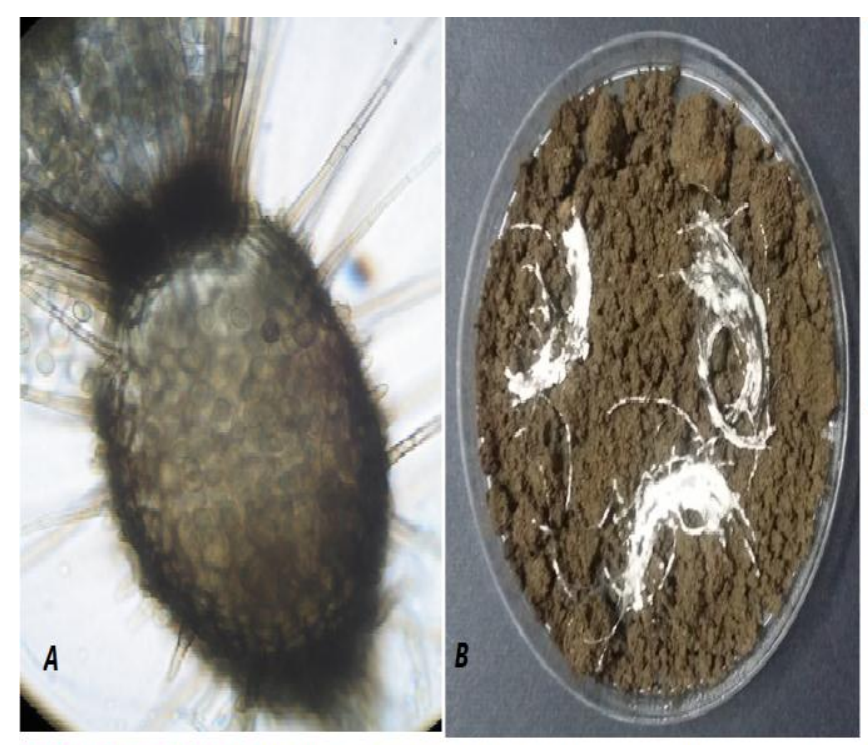

Chaetomium globosum: Dark subglobose Fungal growth on human hair fragment perithecial ascomata with lateral and terminal hairs. Dark olive-brown lemon shaped ascospores are produced.

Growth of Curvularia papendorfii on human hair fragment showing dark hyphae (left), dark conidia on a geniculate conidiophore (right). plated on wet sterile soil, Chrysosporium keratinophilum was isolated

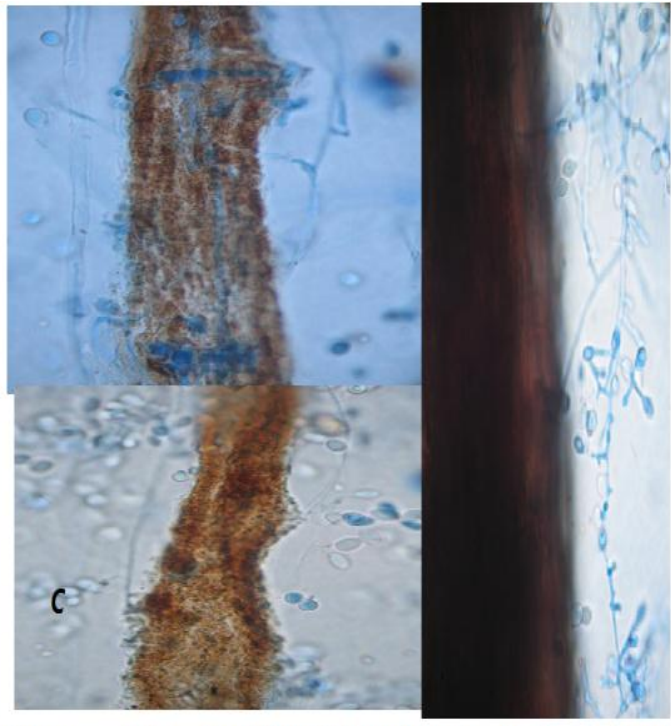

Chrysosporium keratinophilum showing hyphae, ovoid spores and spherical large chlamydospores ondegenerated hair fragments.

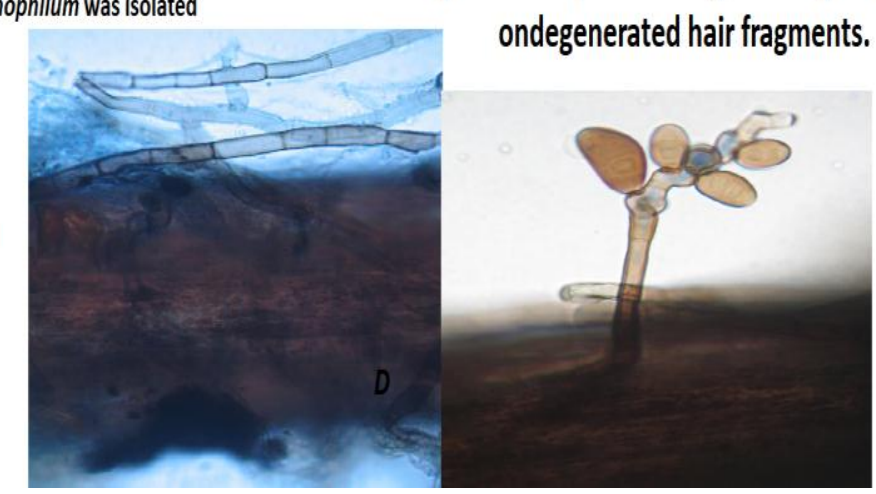

Figure 6. Microscopic images of some fungal species belonging to: A- Chaetomium (X1000), CChrysosporium (X400) and D- Curvularia (X1000) isolated from the hair of workers. Soil plate culture with human hair baits producing white growth of Chrysosporium is included (B). 


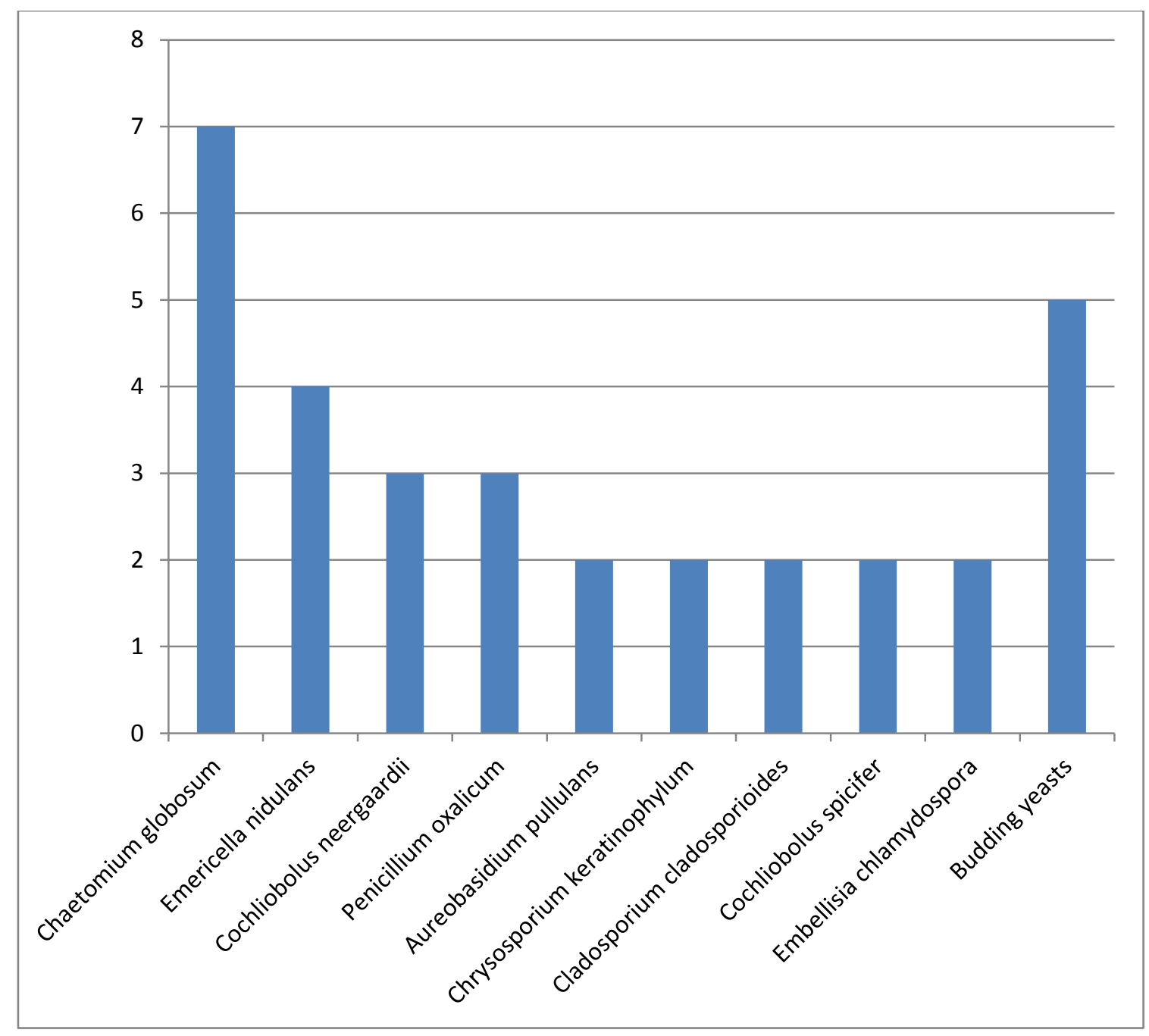

Figure 7: Frequency of keratinophilic fungi in hair samples (Fungi that appeared once were omitted from this chart) 